\title{
Risk factors associated with prolonged viral clearance in patients with a refractory course of COVID-19: a retrospective study
}

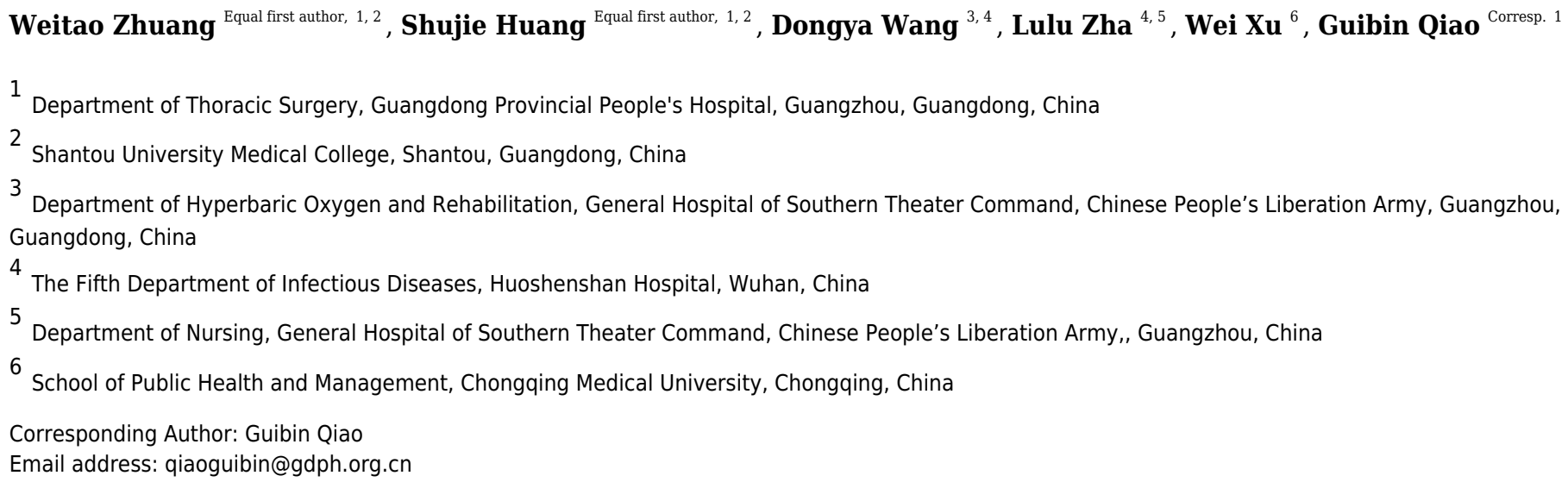

Background: This study aimed to characterize a cohort of patients with a refractory course of COVID-19, and to investigate factors associated with the duration of viral clearance (DoVC).

Materials \& Methods: A total of 65 patients with refractory COVID-19 were retrospectively enrolled from Huoshenshan Hospital. Univariate analysis and multivariate analysis were performed to examine the potential association between clinicopathologic characteristics and the DoVC.

Results: The median DoVC in the overall study cohort was 48 days (ranged from 21 to 104 days). Multivariate analysis indicated that fever at illness onset [Hazard ratio $(\mathrm{HR})=4.897,95 \% \mathrm{Cl}$, 1.809-13.260, $p=0.002$ ], serum level of aspartate aminotransferase (AST) > 21.8 IU/L (HR $=3.010$, $95 \% \mathrm{Cl}, 1.195-7.578, \mathrm{p}=0.019)$, and titer of SARS-CoV-2 IgG $>142.09 \mathrm{AU} / \mathrm{ml}(\mathrm{HR}=3.061,95 \%$ $\mathrm{Cl}, 1.263-7.415, \mathrm{p}=0.013$ ) were the three independent risk factors associated with delayed viral clearance.

Conclusion: The current study suggested that clinical characteristics such as fever at illness onset, a high serum level of AST or SARS-CoV-2 IgG were associated with delayed viral clearance. Patients with these characteristics might need a more individualized treatment strategy to accelerate their recovery from the refractory COVID-19. 
1 Risk factors associated with prolonged viral clearance in patients with a refractory course

2

3

4

6 Affiliations:

7

8

\section{of COVID-19: a retrospective study}

\author{
Weitao Zhuang ${ }^{1,2}$, M.D., Shujie Huang ${ }^{1,2}$, M.D., Dongya Wang ${ }^{3,4}$, B.S.N., Lulu Zha ${ }^{4,5}$, B.S.N., Wei Xu, \\ Ph.D. ${ }^{6}$, Guibin Qiao ${ }^{1}$, M.D., Ph.D.
}

1. Department of Thoracic Surgery, Guangdong Provincial People's Hospital, Guangdong Academy of Medical

Sciences, Guangzhou 510080, China;

2. Shantou University Medical College, Shantou 515041, China;

3. Department of Hyperbaric Oxygen and Rehabilitation, General Hospital of Southern Theater Command,

Chinese People's Liberation Army, Guangzhou, 510010, China

4. The Fifth Department of Infectious Diseases, Huoshenshan Hospital, Wuhan 430113, China;

3 5. Department of Nursing, General Hospital of Southern Theater Command, Chinese People's Liberation Army,

4 Guangzhou, 510010, China

5 6. School of Public Health and Management, Chongqing Medical University, Chongqing 400016, China

* Weitao Zhuang and Shujie Huang contributed equally to this work

Corresponding to:

9 Guibin Qiao, M.D., Ph.D.

Department of Thoracic Surgery

1 Guangdong Provincial People's Hospital, Guangdong Academy of Medical Sciences

22106 Zhongshan Second Road, Guangzhou 510080, China. 


\section{Abstract}

Background: This study aimed to characterize a cohort of patients with a refractory course of COVID-19, and

to investigate factors associated with the duration of viral clearance (DoVC).

Materials \& Methods: A total of 65 patients with refractory COVID-19 were retrospectively enrolled from

Huoshenshan Hospital. Univariate analysis and multivariate analysis were performed to examine the potential association between clinicopathologic characteristics and the DoVC.

Results: The median DoVC in the overall study cohort was 48 days (ranged from 21 to 104 days). Multivariate analysis indicated that fever at illness onset [Hazard ratio $(\mathrm{HR})=4.897,95 \% \mathrm{CI}, 1.809-13.260, \mathrm{p}=0.002$ ], serum level of aspartate aminotransferase $(\mathrm{AST})>21.8 \mathrm{IU} / \mathrm{L}(\mathrm{HR}=3.010,95 \% \mathrm{CI}, 1.195-7.578, \mathrm{p}=0.019)$, and titer of SARS-CoV-2 IgG $>142.09 \mathrm{AU} / \mathrm{ml}(\mathrm{HR}=3.061,95 \% \mathrm{CI}, 1.263-7.415, \mathrm{p}=0.013)$ were the three independent risk factors associated with delayed viral clearance.

Conclusion: The current study suggested that clinical characteristics such as fever at illness onset, a high serum level of AST or SARS-CoV-2 IgG were associated with delayed viral clearance. Patients with these characteristics might need a more individualized treatment strategy to accelerate their recovery from the refractory COVID-19.

\section{Introduction}

As the severe acute respiratory syndrome coronavirus 2 (SARS-CoV-2) sweeps across the globe, there is rising concern that the patients who recovered from COVID-19 may be at risk of reinfection. It was reported that a small percentage of patients were tested positive again after recovery from a previous episode of SARS- 
44 an uncertainty of the criteria to define clinical and virological recovery. ${ }^{3}$ Miscellaneous hypotheses are coming out to address this scientific question, such as false positive results from the leftover genetic materials, ${ }^{4,5}$ persistence of virus within body, cross-contamination from another virus, incorrect sampling methods, ${ }^{6}$ thermal inactivation of samples, ${ }^{7}$ impaired immune response, ${ }^{5}$ even storage of viruses in exosomes and extracellular vesicles. ${ }^{8}$ Given the false negative rates were as high as $30 \%-60 \%$ for SARS-CoV-2 PCR testings in upper respiratory tract or sputum specimens, ${ }^{9,10}$ it is not easy to distinguish between reinfection and prolonged viral clearance. ${ }^{11,12}$ Underlying mechanisms and corresponding patient characteristics of reinfection or prolonged viral clearance may be quite different, which requires personalized treatment strategy. As the medical institutions are overwhelmed by the cumulating patients, what kind of care should be provided to reinfected patients, and how to deal with the patients with a refractory course of diseases, remain to be answered by both physicians and researchers.

The median duration of viral shedding was reported to be about 20 days in many studies. ${ }^{13-17}$ However, prolonged viral clearance is not a rare phenomenon, with the longest duration being 83 days. ${ }^{18-20}$ In this regard, a longer period of post-discharged quarantine and medical observation has been suggested. ${ }^{1,18,20}$ Identifying the patients who are at risk of reinfection or delayed viral clearance might be the first important step to tackle the abovementioned challenge. This may help with optimizing the treatment and preventing the transmission of SARS-CoV-2. Recently, studies are emerging to identify the risk factors associated with longer viral clearance. ${ }^{14,15,17,21}$ However, risk factors of prolonged duration of viral clearance (DoVC) in patients with a refractory course of COVID-19 are less clear and deserve further investigation. Mo, et al. defined a hospital stay of $>10$ days without alleviation of symptoms or radiological improvement to be the refractory COVID19, which was the first study to investigate the clinical characteristics associated with refractory COVID- 
6519 pneumonia. ${ }^{22}$ By their definition, nearly a half of the patients in this study had a refractory course of

66 COVID-19, which suggested a necessity of further stratification. ${ }^{22}$

67 In our study, we characterized a cohort of patients who were deemed having a refractory course of COVID-

19, with the purpose to identify the clinicopathologic risk factors associated with the delayed viral clearance.

70 Patients and Methods

\section{Participants}

A total of 65 inpatients with refractory COVID-19 from Huoshenshan Hospital between February 8, 2020

to March 31, 2020 were enrolled in this retrospective study. All patients had a calculated DoVC longer than 20 days and had a previous history of COVID-19-related hospitalization before admitted to Huoshenshan Hospital.

Patients with a calculated DoVC $\leq 20$ dayswere excluded from this study. The severity of disease was evaluated based on the sixth version of Chinese clinical guideline for COVID-19. ${ }^{23}$ Mild cases referred to mild clinical symptoms with no sign of pneumonia on imaging. General cases were defined as positive clinical symptoms along with pneumonia on thoracic imaging. Patients who met any of the following criteria were classified as severe cases: respiratory rate $\geq 30$ per minute; pulse oxygen saturation $\leq 93 \%$ at resting status; arterial partial pressure of oxygen $(\mathrm{PaO} 2)$ /oxygen concentration $(\mathrm{FiO} 2) \leq 300 \mathrm{mmHg}$; patients with $>50 \%$ progression of lesion volume within 24 to 48 hours on chest imaging. Patients who presented with any of the following conditions were defined as critical cases: Respiratory failure that requires mechanical ventilation; shock; organ failure that

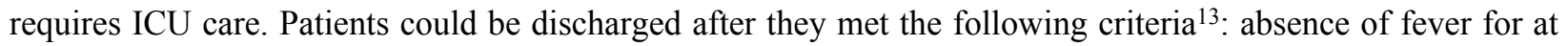
least 3 days, remission of clinical symptoms or chest imaging, and two consecutive negative results for SARS-

CoV-2 RNA in respiratory tract samples obtained at least 24 hours apart. This study was approved by the 
institutional review boards of Huoshenshan Hospital (No. IEC-AF-SL-02), Guangdong Provincial People's Hospital (No.GDRE20200141H) and General Hospital of Southern Theater Command (No.202039), and was carried out in accordance with the Declaration of Helsinki. Electronic forms of informed consents to use their demographic and clinical information were collected from all participants in advance.

\section{Data collection}

A standardized sheet for data collection was used to retrieve the demographic, clinical, laboratory and treatment information from electronic medical records. Given the relatively high rate of false negative nucleic acid testing by nasal/pharyngeal swabs in the previous studies,,${ }^{9,10}$ we raised the standard to define viral clearance, which was in accordance with the abovementioned standard criteria of discharge from hospital. ${ }^{13}$ Therefore, the DoVC was calculated from the date of illness onset (as stated in the history of present illness) to the date of discharge from Huoshenshan hospital. For those who received their negative results of nucleic acid testing but were delayed for discharge due to complications of other organ systems, the DoVC was calculated from the date of illness onset to the date of the second negative nucleic acid testing. Patients with a DoVC $>20$ days were defined to have a refractory course of COVID-19 and satisfied the inclusion criteria of this study. All data were double-checked by two researchers (W. Z. and S. H.) independently for accuracy.

\section{Laboratory tests}

Respiratory samples were tested for SARS-CoV-2 RNA by the real-time reverse transcriptase polymerase chain-reaction (RT-PCR) test (BioGerm, Shanghai, China), following WHO guideline for qRT-PCR. ${ }^{24,25}$ SARS-

CoV-2 IgM and IgG antibodies in blood samples were measured using chemiluminescent immunoassay 
107 (Shenzhen Yahuilong Biotechnology Co., Ltd) as per manufacturer's protocol. The titers higher than 10 of either

IgM or IgG were considered positive infection for SARS-CoV-2.

\section{Treatment}

All patients were provided with necessary supportive care during the first and second hospitalizations, including but not limited to oxygen, antipyretic, antitussive, expectorant, antidiabetic, and antihypertensive agents. For etiological treatment, antivirals, antibiotics, traditional Chinese herbal tea or Chinese patent medicine were used either separately or in combination.

\section{Statistical analysis}

Data of baseline characteristics such as demographic information, reasons of admission, symptoms and signs, comorbidities and treatment details were presented as frequency (percentage), while data of laboratory results were presented as median (interquartile range, IQR). The medians of continuous variables were used as cut-off values to separate the patients into two groups for the sake of comparison, except for C-reactive protein and procalcitonin, where the upper limits of normal range were used. Univariate analysis was performed by using log-rank test to evaluate the association of patient characteristics with DoVC. All variables with $\mathrm{p}$ values $\leq 0.1$ were included in multivariate analysis. Subsequently, log minus log function was used to identify the covariates which did not satisfy the proportional hazard assumption, and these covariates were excluded for the subsequent multivariate analysis. Multivariate analysis was conducted using Cox regression model to identify independent risk factors of prolonged viral clearance. Cases with missing data were excluded from the Cox 
127

128

130

131

132

133

134

135

136

137

regression model. A sensitivity analysis was performed to assess the robustness of the results (see

Supplementary table S1, S2). Finally, Kaplan-Meier method was used to visualize the impact of these risk

factors on the DoVC. All data were performed using IBM SPSS statistics for Windows, Version 25.0

(Armonk, NY: IBM Corp., USA). Figures were generated using the using R software version 3.6.3 (R

Foundation for Statistical Computing, Vienna, Austria).

\section{Results}

\section{Baseline characteristics}

The mean age of patients with a refractory course of COVID-19 was 52.5 years old, and 40 out of 65 patients were male. According to the sixth version of Chinese clinical guideline for COVID-19, ${ }^{23} 51$ out of 68 (78.5\%) patients were classified as general cases, while the others were severe cases. The number of patients who were admitted because of recurrence of symptoms, possible reinfection with positive nucleic acid testing again or referral with persistent symptoms was $3(4.6 \%), 11(16.9 \%)$ and 51 (78.5\%), respectively. Fever (78.5\%), cough (70.8\%), shortness of breath (43.1\%) and fatigue (33.8\%) were the four most prevalent sign and symptoms at illness onset among these patients. Hypertension (26.2\%) was the most common comorbidity, followed by type II diabetes mellitus (18.5\%) (Table 1).

\section{Clinicopathologic information}

Complete blood count and blood biochemistries such as inflammatory seromarkers, renal, cardiac and hepatic function tests were measured upon admission to Huoshenshan Hospital (Table 2). Of the 65 individuals, 59 patients had white blood cell counts in the normal range; 8 patients had increased platelet counts; 30 patients 
148

149

150

151

152

153

154

155

156

157

158

159

160

161

162

163

164

165

166

167

168

had increased C-reactive protein (CRP). Eleven out of 39 patients had increased procalcitonin (PCT). Almost all

patients were normal regrading cardiac, renal and hepatic function tests. Thirty-five patients were tested for the serum antibodies to SARS-CoV-2, of which all patients were positive for SARS-CoV-2 IgG, while only $88.6 \%$ of patients were positive for SARS-CoV-2 IgM. In this study cohort, 26 out of 65 patients (40.0\%) were treated with antiviral agents, including ribavirin, arbidol, oseltamivir and entecavir. Thirty-seven out of 65 patients (56.9\%) were treated with antibiotics, which were mainly cephalosporin and floxacin. Notably, $95.4 \%$ of patients received traditional Chinese herbal tea or Chinese patent medicine, such as Lianhua Qingwen Capsule. Corticosteroid was mainly provided to the severe or critical cases. Twenty-six out of 65 patients had poor sleep quality and required prescription of hypnotics. The median DoVC in the overall study cohort was 48 days (ranged from 21 to 104 days). More than a half of the patients (53.8\%) had a DoVC in the range of 31 to 60 days, and the DoVC was longer than 2 months in $30.8 \%$ of patients.

\section{Risk factors associated with longer viral clearance}

In univariate analyses, several clinicopathologic characteristics were found to be associated with the DoVC, including fever $(p=0.03)$, shortness of breath $(p=0.03)$, and fatigue $(p=0.03)$ at onset, as well as serum levels of CRP $(p=0.01)$ and SARS-CoV-2 IgG $(p=0.01)$ (Table 1, Table 2). Thirty-five patients with complete data were included in the Cox model with a -2 Log Likelihood being 147.9 (overall Chi-square value $=27.909$, $\mathrm{p}<0.001$ ), indicating an acceptable goodness-of-fit of the current model. Sensitivity analyses suggested no statistically significant difference in baseline and clinical characteristics between overall study cohort and patients included in Cox model (see Supplementary table S1, S2).Multivariate analysis suggested that fever at illness onset [Hazard ratio $(\mathrm{HR})=4.897,95 \% \mathrm{CI}, 1.809-13.260, \mathrm{p}=0.002]$, serum level of AST $>21.8 \mathrm{IU} / \mathrm{L}$ 
169

170

171

172

173

174

175

176

177

178

179

180

181

182

183

$(\mathrm{HR}=3.010,95 \% \mathrm{CI}, 1.195-7.578, \mathrm{p}=0.019)$, and titer of SARS-CoV-2 $\mathrm{IgG}>142.09 \mathrm{AU} / \mathrm{ml}(\mathrm{HR}=3.061$, $95 \% \mathrm{CI}, 1.263-7.415, \mathrm{p}=0.013)$ were the three independent risk factors associated with longer viral clearance in the refractory COVID-19 patients (Table 3). The proportional curves of positive viral test specified by three independent factors were depicted using Kaplan-Meier method (Figure 1). The estimated median DoVC was significantly longer in patients with fever at admission (54 days vs. 44 days, $p=0.028$ ), with a titer of SARSCoV-2 IgG higher than $142 \mathrm{AU} / \mathrm{ml}(68$ days vs. 56 days, $\mathrm{p}=0.013)$. Patients with a serum level of AST > 21.8IU/L were deemed to have only a statistically boundary significant longer DoVC ( 56 days vs. 44 days, $p=$ $0.089)$.

\section{Discussion}

The DoVC is central for decision-making of nosocomial isolation precaution and post-discharge quarantine.

Due to the high infectivity of SARS-CoV-2 and the overloaded medical system, a refractory clinical course of COVID-19 could be rather annoying for both patients and medical workers. However, there is still a lack of clinical guideline to deal with this particular group of patients. The current study documented the demographical, epidemiological, laboratory, and many other clinical data in a cohort of patients with a refractory course of COVID-19, with the purpose to identify the risk factors of prolonged hospitalization or viral clearance in these patients. In this retrospective study, 11 out of 65 (16.9\%) were considered as possible reinfection (Table 1), given that they were negative for viral RNA in the former two consecutive nucleic acid tests. However, there was no concrete evidence to support this assumption as the false negative rate of nucleic acid testing was too high. Therefore, they were collectively recognized as patients with a refractory clinical course of COVID-19, 
190

191

along with those with recrudescent or persistent symptoms. It should be noted that this definition did not necessarily signify a severe or critical disease.

Before the cross-study comparison, it is worth noting that the definition of duration of viral shedding or viral clearance has not been unified in the previous studies. ${ }^{14,17,21}$ In consideration of the high false negative rate of nucleic acid testing, we adopted a more conservative criteria to define the date of discharge as the endpoint of viral clearance. As two patients were still in hospitalization due to the complications from other organ systems despite their negative viral RNA results, their DoVC was calculated from the date of illness onset to the date of the second negative nucleic acid testing. The median DoVC was 48 days in our study, which was similar to the finding of one previous study (median $=53.5$ days, IQR $47.75-60.5$ days)..$^{18}$ The duration of viral shedding was about 20 days in many other studies, which was much shorter because the patients with multiple COVID-19related admissions were usually not enrolled. ${ }^{13-17}$ It should be noted that nasal or pharyngeal swabs were mostly used for nucleic testing in these studies, but persistent SARS-CoV-2 RNA has been found elsewhere (e.g. anal swab or stool sample) after negative conversion of nasopharyngeal RT-PCR test. ${ }^{9,26}$

In the current study, the DoVC had a very wide range (Table 2), which indicated that the further stratification among this population might be helpful for personalized management. We have identified the presence of fever at illness onset, AST $>21.8 \mathrm{IU} / \mathrm{L}$ and titer of SARS-CoV-2 IgG $>142.09 \mathrm{AU} / \mathrm{ml}$ to be the three independent risk factors for longer viral clearance in the refractory COVID-19 patients (Table 3, Figure 1). Several other studies have also revealed the presence of fever was significantly associated with prolonged DoVC. ${ }^{27,28}$ These patients were hypothesized to be more severely affected by the SARS-CoV-2 infection in the lungs and thus the prolonged DoVC. ${ }^{27}$ Fever at illness onset may indicate a cytokine storm or a higher viral load at the time of symptom onset, ${ }^{29}$ as the viral load was found to be associated with more severe COVID-19 and a 
211 longer virus-shedding period. ${ }^{30}$ Mildly abnormal liver function test was frequently reported in COVID-19

212 patients, especially the elevated plasma AST.26,30,31 Although a serum level of AST $>21.8$ IU/L in our study not

213 necessarily signified clinical relevance, it was significantly associated with a delayed viral clearance in

214 multivariable analysis. Drug-induced liver injury should be taken into consideration, ${ }^{31}$ because a longer hospital

215 stay usually required more medication, which were potentially hepatotoxic. Other possible underlying

216 mechanisms included direct viral hepatitis or immune-mediated inflammatory response. ${ }^{27}$ The presence of

217 angiotensin-converting enzyme 2 (ACE2) receptor on cholangiocytes and hepatocytes suggested a plausible

218 mechanism of SARS-CoV-2 related hepatotoxicity. ${ }^{33}$ Interestingly, a high level of SARS-CoV-2 IgM was also

219 found to be related to the prolonged viral shedding in a previous study, ${ }^{18}$ which was instead echoed by the level

of IgG in our study. The larger magnitude of SARS-CoV-2 IgG, along with presence of fever at illness onset,

might imply a higher viral load or stronger immune response to the virus. Nevertheless, the underlying

mechanism requires further investigation.

Although less importantly, attention should also be paid to the symptoms such as shortness of breath, fatigue

and the serum level of CRP (Table 1, Table 2). However, we did not observe the impact of age, comorbidities,

severity of disease and treatment on the DoVC. Previous studies revealed multiple risk factors associated with

prolonged viral shedding, including age,${ }^{14,21}$ sex,${ }^{17}$ fever ${ }^{15,34}$ or chest tightness ${ }^{21}$ at admission, comorbidities such

as hypertension and diabetes mellitus, ${ }^{27}$ the duration from symptom onset to admission, ${ }^{15,17}$ albumin level, ${ }^{16}$

antiviral treatment, ${ }^{14,16}$ invasive mechanical ventilation, ${ }^{17}$ and length of hospital stay. ${ }^{15}$ What is noteworthy is

that many studies directly divided the patients into two groups using a cutoff value in the DoVC and perform 
potentially subject to recall bias in retrieving the treatment history. Additionally, we only enrolled patients with

refractory COVID-19, therefore, the results and conclusion should be customized to this specific group of

patients, which limits the generalizability of this study. Finally, the ability to associate clinicopathologic

characteristics with DoVC might be limited by using a convenient instead of statistically determined sample size.

In conclusion, clinical characteristics such as fever at illness onset and a high serum level of AST or SARS-

CoV-2 IgG were associated with delayed viral clearance in patients with a refractory course of COVID-19.

Patients with these characteristics might need a more individualized treatment strategy to accelerate their recovery from the refractory COVID-19.

\section{Acknowledgements}

248 We thank all the patients who provided consents to participate in this retrospective study.

References

1. Mei Q, Li J, Du R, Yuan X, Li M, Li J. Assessment of patients who tested positive for COVID-19 after recovery.

Lancet Infect Dis. 2020. doi: 10.1016/S1473-3099(20)30433-3 
253

254

255

256

257

258

259

260

261

262

263

264

265

266

267

268

269

270

271

272

273

https://wwwreuterscom/article/us-health-coronavirus-southkorea/south-korea-reports-more-recovered-

coronavirus-patients-testing-positive-again-idUSKCN21V0JQ.

3. Alvarez-Moreno CA, Rodriguez-Morales AJ. Testing Dilemmas: Post negative, positive SARS-CoV-2 RT-

PCR - is it a reinfection? Travel Med Infect Dis 2020; 35: 101743. doi: 10.1016/j.tmaid.2020.101743

4. Chaturvedi R, Naidu R, Sheth S, Chakravarthy K. Efficacy of Serology Testing in Predicting Reinfection in Patients with SARS-CoV-2. Disaster Med Public Health Prep 2020: 1-7. doi: 10.1017/dmp.2020.216

5. Batisse D, Benech N, Botelho-Nevers E, Bouiller K, Collarino R, Conrad A. Clinical recurrences of COVID-19 symptoms after recovery: viral relapse, reinfection or inflammatory rebound? J Infect 2020. doi: 10.1016/j.jinf.2020.06.073.

6. Law SK, Leung AWN, Xu C. Is reinfection possible after recovery from COVID-19? Hong Kong Med J 2020; 26(3): 264-5. doi: 10.12809/hkmj208601

7. Pan Y, Long L, Zhang D, Yuan T, Cui S, Yang P, Wang Q, Ren S. Potential False-Negative Nucleic Acid Testing Results for Severe Acute Respiratory Syndrome Coronavirus 2 from Thermal Inactivation of Samples with Low Viral Loads. Clin Chem. 2020;66(6):794-801. doi: 10.1093/clinchem/hvaa091

8. Elrashdy F, Aljaddawi AA, Redwan EM, Uversky VN. On the potential role of exosomes in the COVID19 reinfection/reactivation opportunity. J Biomol Struct Dyn 2020: 1-12. doi: 10.1080/07391102.2020.1790426

9. Wang W, Xu Y, Gao R, Lu R, Han K, Wu G, Tan W. Detection of SARS-CoV-2 in Different Types of Clinical Specimens. JAMA 2020, 12;323(18):1843-1844. doi: 10.1001/jama.2020.3786.

10. Li Y, Yao L, Li J, Chen L, Song Y, Cai Z, Yang C. Stability issues of RT-PCR testing of SARS-CoV-2 for hospitalized patients clinically diagnosed with COVID-19. J Med Virol. 2020;92(7):903-8. doi: 10.1002/jmv.25786

11. Man Z, Jing Z, Huibo S, Bin L, Fanjun Z. Viral shedding prolongation in a kidney transplant patient with 
COVID-19 pneumonia. Am J Transplant 2020. doi: 10.1111/ajt.15996

12. Xiao AT, Tong YX, Zhang S. False negative of RT-PCR and prolonged nucleic acid conversion in COVID-

19: Rather than recurrence. J Med Virol 2020. doi: 10.1002/jmv.25855

13. Zhou F, Yu T, Du R, Fan G, Liu Y, Liu Z, Xiang J, Wang Y, Song B, Gu X, Guan L, Wei Y, Li H, Wu X, Xu J,

Tu S, Zhang Y, Chen H, Cao B. Clinical course and risk factors for mortality of adult inpatients with COVID-19 in Wuhan, China: a retrospective cohort study. Lancet. 2020;395(10229):1054-62. doi: 10.1016/S0140-6736(20)305663

14. Yan D, Liu XY, Zhu YN, Huang L, Dan BT, Zhang GJ, Gao YH. Factors associated with prolonged viral shedding and impact of lopinavir/ritonavir treatment in hospitalised non-critically ill patients with SARS-CoV2 infection. Eur Respir J. 2020;56(1). doi: 10.1183/13993003.00799-2020

15. Qi L, Yang Y, Jiang D, Tu C, Wan L, Chen X, Li Z. Factors associated with the duration of viral shedding in adults with COVID-19 outside of Wuhan, China: a retrospective cohort study. Int J Infect Dis. 2020;96:531-

7. doi: 10.1016/j.ijid.2020.05.045

16. Fu Y, Han P, Zhu R, Bai T, Yi J, Zhao X, Tao M, Quan R, Chen C, Zhang Y, He Q, Jing M, Xiong X, Tian D, Yan W. Risk factors for viral RNA shedding in COVID-19 patients. Eur Respir J. 2020;56(1). doi: $10.1183 / 13993003.01190-2020$

17. Xu K, Chen Y, Yuan J, Yi P, Ding C, Wu W, Li Y, Ni Q, Zou R, Li X, Xu M, Zhang Y, Zhao H, Zhang X, Yu L, Su J, Lang G, Liu J, Wu X, Guo Y, Tao J, Shi D, Yu L, Cao Q, Ruan B, Liu L, Wang Z, Xu Y, Liu Y, Sheng J, Li L. Factors associated with prolonged viral RNA shedding in patients with COVID-19. Clin Infect Dis. 2020. doi: 10.1093/cid/ciaa351

18. Li N, Wang X, Lv T. Prolonged SARS-CoV-2 RNA shedding: Not a rare phenomenon. J Med Virol 2020. 
doi: $10.1002 / j m v .25952$

19. Yang JR, Deng DT, Wu N, Yang B, Li HJ, Pan XB. Persistent viral RNA positivity during the recovery

period of a patient with SARS-CoV-2 infection. J Med Virol 2020. doi: 10.1002/jmv.25940

20. Liu WD, Chang SY, Wang JT, Tsai MJ, Hung CC, Hsu CL, Chang SC. Prolonged virus shedding even

after seroconversion in a patient with COVID-19. J Infect. 2020. doi: 10.1016/j.jinf.2020.03.063

21. Hu X, Xing Y, Jia J, Ni W, Liang J, Zhao D, Song X, Gao R, Jiang F. Factors associated with negative conversion

of viral RNA in patients hospitalized with COVID-19. Sci Total Environ. 2020;728:138812. doi:

10.1016/j.scitotenv.2020.138812

22. Mo P, Xing Y, Xiao Y, Deng L, Zhao Q, Wang H, Xiong Y, Cheng Z, Gao S, Liang K, Luo M, Chen T, Song S,

Ma Z, Chen X, Zheng R, Cao Q, Wang F, Zhang Y. Clinical characteristics of refractory COVID-19 pneumonia in

Wuhan, China. Clin Infect Dis. 2020 Mar 16:ciaa270. doi: 10.1093/cid/ciaa270.

23. National Health Commission of China. Chinese management guideline for COVID-19 (version 6.0).

https://www.chinadaily.com.cn/pdf/2020/1.Clinical.Protocols.for.the.Diagnosis.and.Treatment.of.COVID-

19.V7.pdf (accessed Feb 20, 2020; in Chinese).

24. Corman VM, Landt O, Kaiser M, Molenkamp R, Meijer A, Chu DK, Bleicker T, Brunink S, Schneider J,

Schmidt ML, Mulders DG, Haagmans BL, van der Veer B, van den Brink S, Wijsman L, Goderski G, Romette

JL, Ellis J, Zambon M, Peiris M, Goossens H, Reusken C, Koopmans MP, Drosten C. Detection of 2019 novel

coronavirus (2019-nCoV) by real-time RT-PCR. Euro Surveill. 2020;25(3). doi: 10.2807/1560-

25. Organization WH. Laboratory testing for 2019 novel coronavirus (2019-nCoV) in suspected human cases. 
316 Interim guidance. Jan 17, 2020. . . https:/wwwwhoint/publications-detail/laboratory-testing-for-2019-novel-

317 coronavirus-in-suspected-human-cases-20200117 (accessed Feb 20, 2020)

318 26. Kipkorir V, Cheruiyot I, Ngure B, Misiani M, Munguti J. Prolonged SARS-Cov-2 RNA Detection in

319 Anal/Rectal Swabs and Stool Specimens in COVID-19 Patients After Negative Conversion in Nasopharyngeal

RT-PCR Test. J Med Virol 2020. doi: 10.1002/jmv.26007

27. Zhou Y, Ding F, Bao W, Xue Y, Han L, Zhang X, Zhang P, Ji Y, Yin D, Bao A, Luo S, Xu Z, Liu J, Zhang M.

Clinical features in coronavirus disease 2019 (COVID-19) patients with early clearance and prolonged shedding of

severe acute respiratory syndrome coronavirus 2 (SARS-CoV-2) RNA. Ann Transl Med. 2021;9(8):665. doi:

10.21037/atm-21-445.

28. Bennasrallah C, Zemni I, Dhouib W, Sriha H, Mezhoud N, Bouslama S, Taboubi W, Beji MO, Kacem M,

Abroug H, Fredj MB, Loussaief C, Belguith AS. Factors associated with a prolonged negative conversion of viral

RNA in patients with COVID-19. Int J Infect Dis. 2021;105:463-9. doi: 10.1016/j.ijid.2021.02.089.

29. Chau AS, Weber AG, Maria NI, Narain S, Liu A, Hajizadeh N, Malhotra P, Bloom O, Marder G, Kaplan B. The

Longitudinal Immune Response to Coronavirus Disease 2019: Chasing the Cytokine Storm. Arthritis Rheumatol.

2021;73(1):23-35. doi: 10.1002/art.41526.

30. Liu Y, Yan LM, Wan L, Xiang TX, Le A, Liu JM, Peiris M, Poon LLM, Zhang W. Viral dynamics in mild and

severe cases of COVID-19. Lancet Infect Dis. 2020;20(6):656-7. doi: 10.1016/S1473-3099(20)30232-2.

31. Bertolini A, van de Peppel IP, Bodewes F, Moshage H, Fantin A, Farinati F, Fiorotto R, Jonker JW, Strazzabosco

M, Verkade HJ, Peserico G. Abnormal liver function tests in COVID-19 patients: relevance and potential

pathogenesis. Hepatology. 2020. doi: 10.1002/hep.31480

32. Zarifian A, Bidary MZ, Arekhi S, Rafiee M, Gholamalizadeh H, Amiriani A, Ghaderi MS, Khadem- 
Rezaiyan M, Amini M, Ganji A. Gastrointestinal and hepatic abnormalities in patients with confirmed COVID-

19: a systematic review and meta-analysis. J Med Virol. 2020. doi: 10.1002/jmv.26314

33. Chai X, Hu L, Zhang Y, Han W, Lu Z, Ke A, Zhou J, Shi G, Fang N, Fan J, Cai J, Fan J, Lan F. Specific

ACE2 expression in cholangiocytes may cause liver damage after 2019-nCoV infection.

bioRxiv 2020.02.03.931766. doi: 10.1101/2020.02.03.931766.

34. Lu Y, Li Y, Deng W, Liu M, He Y, Huang L, Lv M, Li J, Du H. Symptomatic Infection is Associated with

Prolonged Duration of Viral Shedding in Mild Coronavirus Disease 2019: A Retrospective Study of 110 Children in

Wuhan. Pediatr Infect Dis J. 2020;39(7):e95-e9. doi: 10.1097/INF.0000000000002729

Figure Legend

Figure 1. Proportional curves of positive viral testing. Comparison of duration of viral clearance between

patients (A) with or without fever at onset; (B) with lower $(\leq 142.09 \mathrm{AU} / \mathrm{ml})$ or higher $(>142.09 \mathrm{AU} / \mathrm{ml})$ levels

of SARS-CoV-2 IgG; (C) with lower ( $\leq 21.8 \mathrm{IU} / \mathrm{L})$ or higher (> 21.8 IU/L) levels of aspartate

aminotransferase (AST). Log-rank test was used for comparison. 


\section{Table $\mathbf{1}$ (on next page)}

Table 1 Baseline characteristics of patients with a refractory clinical course of COVID-19 
1 Table 1 Baseline characteristics of patients with a refractory clinical course of COVID-19

\begin{tabular}{|c|c|c|}
\hline Baseline Characteristics & $\begin{array}{c}\text { Study cohort }=65 \\
\text { Frequency }(\%) / \text { Mean } \pm \text { SD }\end{array}$ & $\begin{array}{c}\text { p } \\
\text { value* }\end{array}$ \\
\hline Age (years) & $52.5 \pm 14.1$ & 0.85 \\
\hline$\leq 60$ & $43(66.2)$ & \\
\hline$>60$ & $22(33.8)$ & \\
\hline Male & $40(61.5)$ & 0.76 \\
\hline Reasons of admission & & 0.89 \\
\hline Recurrence of symptoms & $3(4.6)$ & \\
\hline $\begin{array}{l}\text { Possible reinfection with positive } \\
\text { nucleic acid testing again }\end{array}$ & $11(16.9)$ & \\
\hline Referral with persistent symptoms & $51(78.5)$ & \\
\hline \multicolumn{3}{|l|}{ Symptoms and signs at illness onset } \\
\hline Fever & $51(78.5)$ & $\mathbf{0 . 0 3}$ \\
\hline Shortness of breath & $28(43.1)$ & $\mathbf{0 . 0 3}$ \\
\hline Dyspnea & $5(7.7)$ & 0.17 \\
\hline Chest tightness & $11(16.9)$ & 0.77 \\
\hline Myalgia & $13(20.0)$ & 0.97 \\
\hline Dry cough & $16(24.6)$ & 0.70 \\
\hline Productive cough & $30(46.2)$ & 0.82 \\
\hline Fatigue & $22(33.8)$ & $\mathbf{0 . 0 3}$ \\
\hline Diarrhea & $4(6.2)$ & 0.99 \\
\hline Headache & $3(4.6)$ & 0.99 \\
\hline
\end{tabular}

\section{Comorbidities}

Hypertension

$17(26.2) \quad 0.35$

Type II diabetes mellitus

$12(18.5) \quad 0.91$

Coronary artery disease

$4(6.2)$

0.24

COPD

3 (4.6)

0.94

Hepatitis B

$3(4.6)$

0.50

Malignancy

$2(3.1)$

0.67

Smoker

$5(7.7)$

0.80

Alcohol user

$2(3.1)$

0.99

Severity of COVID-19 pneumonia

0.40 
Mild

General

Severe
0

$51(78.5)$

$14(21.5)$

0

2 *Univariate analysis to determine the association of baseline characteristics with duration of viral clearance by

3 using log-rank test. COPD, chronic obstructive pulmonary diseases. Variables with p value in bold were included

4 in multivariable analysis. 


\section{Table 2 (on next page)}

Table 2 Clinicopathologic characteristics of patients with a refractory clinical course of COVID-19 
1 Table 2 Clinicopathologic characteristics of patients with a refractory clinical course of COVID-19

\begin{tabular}{|c|c|c|c|}
\hline Clinicopathologic characteristics & $\begin{array}{c}\text { Study cohort }=65 \\
\text { Frequency }(\%) / \\
\text { Median }(Q 1, Q 3) \\
\end{array}$ & $\begin{array}{c}\text { Normal } \\
\text { range }\end{array}$ & p val \\
\hline \multicolumn{4}{|l|}{ Laboratory results } \\
\hline $\mathrm{WBC} \#\left(\times 10^{\wedge} 9 / \mathrm{L}\right)$ & $6.00(5.05,7.10)$ & $3.5-9.5$ & 0.5 \\
\hline $\mathrm{RBC} \#\left(\times 10^{\wedge} 12 / \mathrm{L}\right)$ & $4.10(3.80,4.45)$ & $4.3-5.8$ & 0. \\
\hline Platelet \# $\left(\times 10^{\wedge} 9 / \mathrm{L}\right)$ & $230.00(184.5,291.50)$ & $125-350$ & 0.0 \\
\hline NLR & $2.35(1.77,3.45)$ & & \\
\hline C-reactive protein $(\mathrm{mg} / \mathrm{L})$ & $2.90(1.59,9.66)$ & $0-4$ & $\mathbf{0 .}$ \\
\hline Normal & $35(53.8)$ & & \\
\hline Increased & $30(46.2)$ & & \\
\hline Procalcitonin $(\mathrm{ng} / \mathrm{ml})(\mathrm{n}=38)$ & $0.05(0.03,0.06)$ & $0-0.05$ & 0.1 \\
\hline Normal & $27(71.1)$ & & \\
\hline Increased & $11(28.9)$ & & \\
\hline Albumin $(\mathrm{g} / \mathrm{L})$ & $38.15(35.35,40.65)$ & $40-55$ & 0.5 \\
\hline $\operatorname{ALT}(\mathrm{IU} / \mathrm{L})$ & $30.15(16.60,49.85)$ & $9-50$ & \\
\hline $\mathrm{AST}(\mathrm{IU} / \mathrm{L})$ & $21.80(17.25,29.20)$ & $9-60$ & 0. \\
\hline HBDH (IU/L) $(n=48)$ & $152.90(128.20,193.43)$ & $24-190$ & 0. \\
\hline LDH $(\mathrm{IU} / \mathrm{L})(\mathrm{n}=48)$ & $181.15(156.83,239.95)$ & $120-250$ & 0 . \\
\hline $\mathrm{CK}(\mathrm{IU} / \mathrm{L})(\mathrm{n}=48)$ & $48.05(34.35,70.43)$ & $24-190$ & 0. \\
\hline CK-MB (IU/L) (n=48) & $7.75(6.40,11.50)$ & $0-24$ & 0. \\
\hline SARS-CoV-2 IgM $(n=35)(A U / m l)$ & $39.01(17.74,90.51)$ & $<10$ & 0. \\
\hline SARS-CoV-2 IgG $(\mathrm{n}=35)(\mathrm{AU} / \mathrm{ml})$ & $142.09(116.40,179.86)$ & $<10$ & $\mathbf{0 .}$ \\
\hline
\end{tabular}

Treatment details

Antivirals

Antibiotics

Traditional Chinese medicine

Corticosteroid

Hypnotics

Duration of viral clearance

21-30 days

31-60 days

$\begin{array}{lll}26(40.0) & - & 0.12 \\ 37(56.9) & - & 0.24 \\ 62(95.4) & - & 0.11 \\ 12(18.5) & - & 0.27 \\ 26(40.0) & - & 0.66 \\ 49(35,65) & - & - \\ 10(15.4) & & \\ 35(53.8) & & \end{array}$


$>60$ days

$20(30.8)$

$2 *$ Univariate analysis to determine the association of clinicopathologic characteristics with duration of viral 3 clearance by using log-rank test. Patients were categorized into two groups based on the median value of 4 laboratory results except for C-reactive protein and procalcitonin. NLR, neutrophil-lymphocyte ratio; ALT, 5 Alanine aminotransferase; AST, Aspartate aminotransferase; HBDH, $\alpha$-Hydroxybutyrate dehydrogenase; $6 \mathrm{LDH}$, lactase dehydrogenase; CK, creatine kinase; CK-MB, creatine kinase isoenzyme. Variables with $\mathrm{p}$ value 7 in bold were included in multivariable analysis. 


\section{Table 3(on next page)}

Table 3 Multivariate analysis using Cox regression model $(n=36)$ 
1 Table 3 Multivariate analysis using Cox regression model $(\mathrm{n}=35)$

\begin{tabular}{|c|c|c|c|c|}
\hline \multirow{2}{*}{ Variables (Reference) } & \multirow{2}{*}{$\begin{array}{c}\text { Hazard } \\
\text { Ratio }\end{array}$} & \multicolumn{2}{|c|}{ 95\% Confidence Interval } & \multirow{2}{*}{ p value } \\
\hline & & Lower & Upper & \\
\hline \multicolumn{5}{|l|}{ Fever (No) } \\
\hline Yes & 4.897 & 1.809 & 13.260 & 0.002 \\
\hline \multicolumn{5}{|l|}{ Shortness of breath (No) } \\
\hline Yes & 1.239 & 0.436 & 3.521 & 0.687 \\
\hline \multicolumn{5}{|l|}{ Fatigue (No) } \\
\hline Yes & 1.515 & 0.569 & 4.034 & 0.406 \\
\hline \multicolumn{5}{|l|}{ Platelet \# $\left(\leq 230 \times 10^{\wedge} 9 / \mathrm{L}\right)$} \\
\hline$>230 \times 10^{\wedge} 9 / \mathrm{L}$ & 0.479 & 0.205 & 1.123 & 0.091 \\
\hline \multicolumn{5}{|l|}{$\mathrm{NLR}(\leq 2.35)$} \\
\hline$>2.35$ & 2.831 & 0.984 & 8.145 & 0.054 \\
\hline \multicolumn{5}{|l|}{$\mathrm{CRP}(\leq 4 \mathrm{mg} / \mathrm{L})$} \\
\hline$>4 \mathrm{mg} / \mathrm{L}$ & 0.311 & 0.087 & 1.115 & 0.073 \\
\hline \multicolumn{5}{|l|}{ AST ( $\leq 21.8 \mathrm{IU} / \mathrm{L})$} \\
\hline$>21.8 \mathrm{IU} / \mathrm{L}$ & 3.010 & 1.195 & 7.578 & 0.019 \\
\hline \multicolumn{5}{|c|}{ SARS-CoV-2 IgG $(\leq 142.09)$} \\
\hline$>142.09$ & 3.061 & 1.263 & 7.415 & 0.013 \\
\hline
\end{tabular}

2 NLR, neutrophil-lymphocyte ratio; CRP, C-reactive protein; AST, aspartate aminotransferase; SARS-CoV-2

$3 \mathrm{IgG}$, Severe acute respiratory syndrome coronavirus 2 immunoglobulin $\mathrm{G}$. 
Figure 1

Figure 1 Proportional curves of positive viral testing.
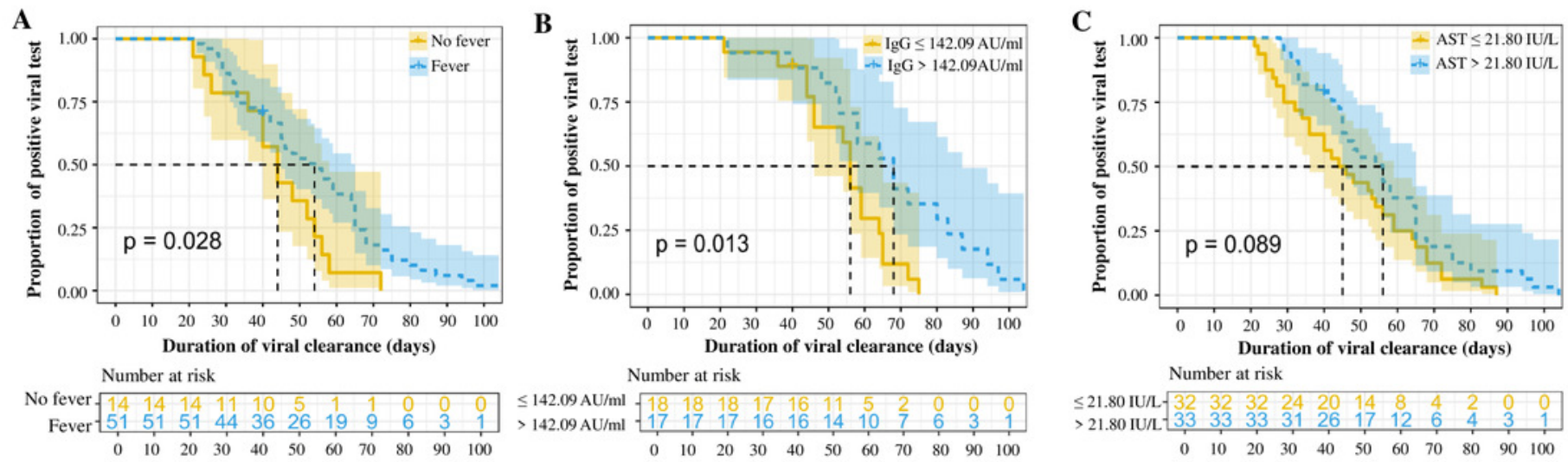